\title{
Validation of Edinburgh post natal depression scale in post-natal woman from a tertiary referral center in South India
}

\author{
Rashmi A. G., Shubhashri N. S.* \\ Department of Obstetrics and Gynecology, Rajarajeswari Medical College and Hospital, Bengaluru, Karnataka, India \\ Received: 17 June 2020 \\ Accepted: 10 July 2020

\section{*Correspondence:} \\ Dr. Shubhashri N. S., \\ E-mail: shubhashri.n.s@gmail.com \\ Copyright: (C) the author(s), publisher and licensee Medip Academy. This is an open-access article distributed under \\ the terms of the Creative Commons Attribution Non-Commercial License, which permits unrestricted non-commercial \\ use, distribution, and reproduction in any medium, provided the original work is properly cited.
}

\begin{abstract}
Background: Pregnancy and childbirth are two most important life-changing events. Post-partum depression can affect mother and has a wide spectrum of presentation depending upon various social factors. Studies suggest that the incidence of postnatal depression among women of high social strata is $13-19 \%$ while the incidence is $11-42 \%$ among women with limited social support. The present study aims to study postnatal depression and its causes in a postnatal mother in all the aspects of social, physical, cultural and psychiatric grounds in the Indian scenario with the help of the Edinburgh postnatal depression scale (EPDS).

Methods: From $1^{\text {st }}$ July 2019 to $31^{\text {st }}$ December 2019, a total 300 postnatal women between 1 to 6 weeks of the postpartum period participated and during their stay in the hospital responded to EPDS. The study was purposive sampling, and full consent of the study subjects was taken before the start of the study.

Results: In this study, we found $20.1 \%$ of a woman affected by post-partum in South India. The higher percentage of severe depression was seen in the primary gravida (20\%). The risk factors such as availability of postnatal care (with NICU admission), the woman with medical complications, late childbirth or delayed childbirth after marriage, multiparity, delivery via caesarean and nuclear family showed significant relationship $(\mathrm{p}<0.005)$ with depression.

Conclusions: The present study, with a Post-natal depression of $20.1 \%$ along with the enumerated risk factors, suggest that the causes for postpartum depression (PPD) among working Indian woman, reflect a change to an urbancentric lifestyle. Further evaluation of these risk factors needs to be made and a routine screening of Postpartum depression (PPD) can help in improving maternal and child health.
\end{abstract}

Keywords: Cross-sectional study, Edinburgh postnatal depression scale, Mother, Newborn care, Postnatal mother, Postnatal period

\section{INTRODUCTION}

Pregnancy is a well-known term in human's life. Both the postpartum and the pregnancy are a period of higher risk for the beginning of several psychiatric disorders. In the list of these psychiatric disorders, postnatal depression is most common. ${ }^{1}$ Non-psychotic episodes of depression can be defined in postnatal depression or PND, which includes symptoms such as loss of energy, lack of interest, and insomnia. These symptoms often appear during the first 6 weeks post-delivery. ${ }^{1}$ Cases of postnatal depression are reported on a wide scale worldwide. The incidence of postpartum blues is $15-85 \%$ within first 10 days after delivery and postpartum psychosis has an incidence on 1 in 500 women. $^{2}$ The studies on postpartum depression (PPD) from various developing countries reveal an incidence of $12-36 \% .^{3-7}$ The incidence of PPD India ranges between $11-26.3 \% .^{8-11}$ It is reflected as a serious health issue, because of its direct impact on mother and child health. ${ }^{12}$ Precise estimation of depression in post-partum and pregnant cases is tough to define, because of hesitation, family environment and culture, which negatively affect methods of determination of the accurate rate of such cases. ${ }^{13,14} \mathrm{~A}$ few published 
reports give shreds of evidence of a higher rate of postpartum depression in Asian women as compared to that of North American women. ${ }^{15}$ Post-partum depression is affected by multiple factors such as the economic background of the woman, her physical condition (more in the obese women and with medical risk), her psychosocial background and demographic background. Few more factors such as the pressure of birth of the baby girl, rituals, financial status, domestic violence, and lack of social support added more factors in the aetiology of postpartum depression, especially in developing countries. $^{6,8}$

Post-partum depression prompts recurrent or chronic depression, which can even affect the relationship of a mother with her child and also child's development. ${ }^{16-18}$ It has been studied that the child of the mother suffering from post-partum depression also suffers from various problems such as behavioural, interpersonal and cognitive problems. ${ }^{19}$ The shreds of evidence collected from the literature suggest that in developing countries, the children of mothers who are suffering from postpartum depression are stunted as well as underweight. Due to postpartum depression, the mother is unable to breastfeed her baby properly and take care of her child's health. ${ }^{18}$ There has been a decline in the maternal mortality rate in India as a result of better maternal care during pregnancy and at the time of delivery. ${ }^{20}$

\section{Rationale}

The studies on postpartum depression is increasing day by day in India, which is providing shreds of evidence and guidelines for the better understanding of the aetiology of postpartum depression and to improve maternal and child health. ${ }^{20}$

Objective of this study was to determine the prevalence of postnatal depression among women and to validate the EPDS as a screening tool for postpartum depression in post-natal women attending tertiary care hospital in Bangalore.

\section{METHODS}

\section{Study design: prospective observational study}

Authors enrolled 300 adult women of 1 to 6 weeks postpartum who could communicate in Kannada and/or English language and were registered with department of obstetrics and gynecology, Rajarajeshwari Medical College and Hospital, Bengaluru, Karnataka, India.

Women with previously diagnosed depression were excluded from the study.

At $95 \%$ confidence levels, 5\% margin of error, and considering $26 \%$ as the estimated prevalence of postpartum depression among women living in India. The final sample size was calculated to be 296 .

A total 300 consecutive women with a post-partum period ranging from one to six weeks registered with department of obstetrics and gynecology of Rajarajeshwari Medical college, Bengaluru from July 2019 to December 2019. Informed consent was obtained. The sampling method was purposive sampling. EDS tool was used.

\section{Inclusion criteria}

- An 18 years of age or older, participating voluntarily in the study, and speaking and reading Kannada and/or English attending postnatal clinic of Rajarajeshwari Medical College and Teaching Hospital, Bengaluru during the period JulyDecember 2019.

\section{Exclusion criteria}

- Pregnant women with a previous history of any other severe mental disorder, suicidal ideation or on antidepressants were excluded from the study ${ }^{21}$

- Women who were unable to comprehend were also excluded

- Women with stillbirths and abortions.

EPDS is a self-rating questionnaire that reflects the subject's feelings over the past 7 days. It includes ten questions, with each item scored on a four-point scale from 0 to 3 , depending on the severity or duration of each symptom. Total scores range from 0-30 and completion takes around 5 minutes. ${ }^{21}$ The Socio-economic class was calculated using Modified Kuppuswami Scale. ${ }^{22}$

In a primary care setting, the score of $<13$ was recommended to identify the women at risk of depression, whereas the score of $\geq 13$ likely reflects moderate to severe depression. ${ }^{21}$ In the present study cutoff points of $9 / 10$ and $12 / 13$ as markers of possible minor and major depression, were also taken. ${ }^{22}$

The institutional review board of Rajarajeshwari Medical College and Hospital approved this study. The purpose of the study was explained and informed consent was obtained from the participants.

\section{Statistical analysis}

Statistical data analysis was done with the help of the Social science statistical package version 22. Statistical Package for the social sciences (SPSS). Authors also performed the chi-square test and Fisher's exact test.

\section{RESULTS}

Authors studied 300 women registered in the tertiary care center, who visited the center for post-natal follow-up, 
after satisfying the exclusion and the inclusion criteria of the study. Among the registered woman out of 300, only 290 participated in the study with consent and 10 were non-participant. The non-participation rate of the present study was $13 \%$. The mean age of the study participants was $25 \pm 1.0$ years, range 21-29 years. Mean of duration of married life $2.5 \pm 2$ years. Most of the studied women were having a good relationship with their husband, they were educated (98\%), the salaried woman (98), residing in a nuclear family $(95 \%)$ and belongs to middle-class families (99) (Table 1).

Table 1: Different primary studied parameters in the patients with post-partum in the registered in a tertiary care centre.

\begin{tabular}{|lllll|}
\hline Variables & & $\begin{array}{l}\text { Number of } \\
\text { patients }(\mathbf{n}=\mathbf{2 9 0})\end{array}$ & $\begin{array}{l}\text { With post- } \\
\text { partum }(\mathbf{n}=\mathbf{2 5 0})\end{array}$ & $\begin{array}{l}\text { Without post- } \\
\text { partum (n=40) }\end{array}$ \\
\hline Age (21-29) (mean SD) & 25 & 24 & 19 \\
\hline Education & Graduate (in \%) & 100 & 98 & 2 \\
\hline Family structure & Nuclear (in \%) & 95 & 95 & 1 \\
\cline { 2 - 5 } & Joint (in \%) & 5 & - & 5 \\
\hline Occupation & Home maker (in \%) & 2 & - & 01 \\
\cline { 2 - 5 } & Salaried/daily worker (in \%) & 98 & 96 & - \\
\hline $\begin{array}{l}\text { Duration of marriage } \\
\text { (1-11 years) (mean SD) }\end{array}$ & $\begin{array}{l}\text { Middle class/lower middle } \\
\text { Income of the family }\end{array}$ & 99 & 2.56 & 3 \\
\hline
\end{tabular}

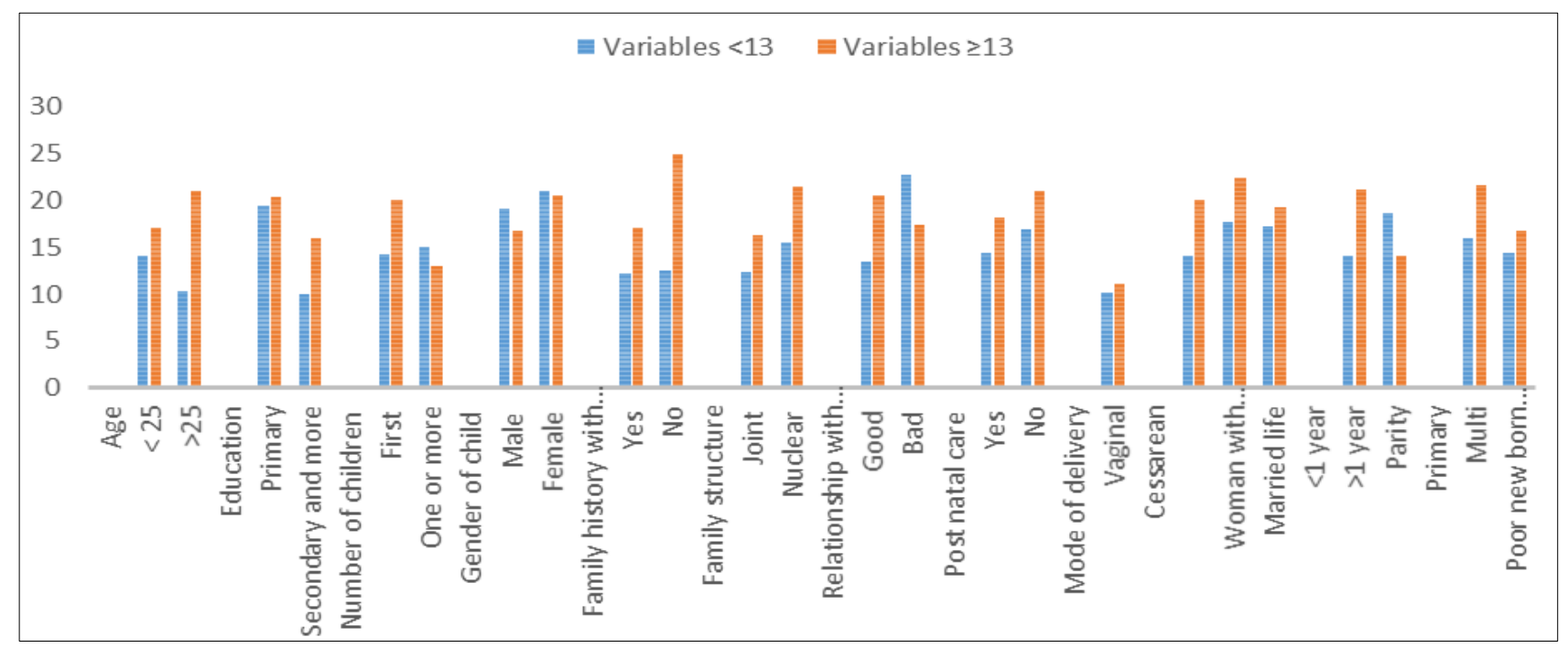

Figure 1: The EPDS score of different studied risk factors responsible for post-partum in percentage.

Most of the participants were self-dependent and had a delivery in the first year of their marriage. A large number of total participants have delivered by Caesarean section. Rest all had vaginal delivery. Out of total registered woman every tenth postnatal woman had medical complications such as eclampsia, pre-eclampsia, anaemia, diabetes, hypertension, and PCOD. The woman has a history of stillbirth and abortions were excluded from the study.

The EPDS score showed a higher percentage $(20.3 \%)$ of severe depression risk in a woman with primary education as compared to a woman with secondary education. A higher percentage of severe depression was seen in the primary gravida $(20 \%)$, while moderate depression was seen in the woman having a second or third child. In our study the gender of the new-born and family history of depression was not found significant for severe depression, the woman showed moderate depression. The univariate examination of risk factors such as (availability of postnatal care with NICU admission), woman with medical complications, late childbirth or delayed childbirth after marriage, multiparity, delivery via caesarean and nuclear family) showed significant relationship $(\mathrm{p}<0.005)$ with depression (Table 2, Figure 1). 
Table 2: The associated factors with the risk for post-partum in admitted patients where $\mathbf{n = 2 9 0}$.

\begin{tabular}{|c|c|c|c|c|c|c|}
\hline \multirow{3}{*}{ Variables } & \multicolumn{4}{|c|}{ EPDS score } & \multirow{3}{*}{$\begin{array}{l}\text { Total woman } \\
\text { participated in the study }\end{array}$} & \multirow{3}{*}{ p value } \\
\hline & \multicolumn{2}{|l|}{$<13$} & \multicolumn{2}{|l|}{$\geq 13$} & & \\
\hline & Number & $\%$ & Number & $\%$ & & \\
\hline \multicolumn{6}{|l|}{ Age } & \multirow{3}{*}{0.594} \\
\hline$<25$ & 40 & $14.1 \%$ & 50 & $17 \%$ & 282 & \\
\hline$>25$ & 24 & $10.3 \%$ & 50 & $21 \%$ & 232 & \\
\hline \multicolumn{6}{|l|}{ Education } & \multirow{3}{*}{0.412} \\
\hline Primary & 48 & $19.43 \%$ & 52 & $20.3 \%$ & 248 & \\
\hline Secondary and more & 20 & $50 \%$ & 29 & $16 \%$ & 240 & \\
\hline \multicolumn{6}{|l|}{ Number of children } & \multirow{3}{*}{0.0368} \\
\hline First & 50 & $14.25 \%$ & 110 & $20 \%$ & 260 & \\
\hline One or more & 114 & $15 \%$ & 38 & $13 \%$ & 252 & \\
\hline \multicolumn{6}{|l|}{ Gender of child } & \multirow{3}{*}{0.008} \\
\hline Male & 38 & $19.18 \%$ & 50 & $16.81 \%$ & 288 & \\
\hline Female & 30 & $21.07 \%$ & 76 & $20.46 \%$ & 206 & \\
\hline \multicolumn{6}{|c|}{ Family history with depression } & \multirow{3}{*}{$0.0341^{*}$} \\
\hline Yes & 21 & $12.25 \%$ & 32 & $67 \%$ & 164 & \\
\hline No & 30 & $12.5 \%$ & 58 & $25 \%$ & 248 & \\
\hline \multicolumn{6}{|l|}{ Family structure } & \multirow{3}{*}{$0.39 *$} \\
\hline Joint & 31 & $12.42 \%$ & 40 & $16.27 \%$ & 240 & \\
\hline Nuclear & 35 & $15.57 \%$ & 60 & $21.4 \%$ & 266 & \\
\hline \multicolumn{6}{|l|}{ Relationship with husband } & \multirow{3}{*}{0.0076} \\
\hline Good & 31 & $13.46 \%$ & 47 & $20.5 \%$ & 230 & \\
\hline $\mathrm{Bad}$ & 34 & $22.66 \%$ & 116 & $77.33 \%$ & 150 & \\
\hline \multicolumn{6}{|l|}{ Post-natal care } & \multirow{3}{*}{$0.0052 * *$} \\
\hline Yes & 38 & $14.39 \%$ & 48 & $18.1 \%$ & 264 & \\
\hline No & 28 & $16.86 \%$ & 58 & $21 \%$ & 266 & \\
\hline \multicolumn{6}{|l|}{ Mode of delivery } & \multirow{3}{*}{0.0067} \\
\hline Vaginal & 25 & $10.09 \%$ & 28 & $11.1 \%$ & 250 & \\
\hline Caesarean & 28 & $14.09 \%$ & 32 & $20.1 \%$ & 200 & \\
\hline $\begin{array}{l}\text { Woman with complication } \\
\text { during pregnancy }\end{array}$ & 40 & $17.74 \%$ & 51 & $22.4 \%$ & 226 & 0.0062 \\
\hline \multicolumn{6}{|l|}{ Married life } & \multirow{3}{*}{0.043} \\
\hline$<1$ year & 36 & $17.30 \%$ & 42 & $19.23 \%$ & 208 & \\
\hline$>1$ year & 32 & $14.03 \%$ & 49 & $21.23 \%$ & 208 & \\
\hline \multicolumn{6}{|l|}{ Parity } & \\
\hline Primary & 42 & $18.69 \%$ & 34 & $14.03 \%$ & 230 & $0.004 * *$ \\
\hline Multi & 39 & $16 \%$ & 44 & $21.56 \%$ & 230 & \\
\hline $\begin{array}{l}\text { Poor new born health (NICU } \\
\text { admission) }\end{array}$ & 36 & $14.4 \%$ & 42 & $16.8 \%$ & 250 & $0.006 * *$ \\
\hline
\end{tabular}

* Significant, ** Fisher's exact test.

\section{DISCUSSION}

\section{Main findings}

A large proportion of the woman admitted in tertiary care center from the duration of 1-6 weeks of delivery, participated in our study, were at the risk of postpartum depression. Post-partum was found associated with the caesarean section, nuclear family, poor child health with NICU admission, bad relationship with husband and in- laws, delayed childbirth, medical complication, and multiparity.

\section{Interpretation}

Pregnancy and child are two unique events of life and the associated stress cannot be reduced due to cultural and social backgrounds are vital collectively based on experiences of the woman. ${ }^{22,23}$ The socio-economic status, religion, culture, and literacy show a significant influence on mental health. The present study is an 
endeavor to explore the above-mentioned biological factors which cause the risk of depression in new mothers. In the present study, authors report $20.1 \%$ postpartum, and it is considered to be high. The studies previously published have reported a lower rate of postpartum in India, near about $11 \%$. A wide range of prevalence of postpartum was seen in UAE $15.8 \%$, Brazil $20.7 \%$, China $11 \%$, Pakistan $40 \%$, and South Africa $34.7 \% .^{24-27}$ In this study, authors tried to estimate the prevalence of postpartum in Indian scenario, through the EPDS screening tool. Nuclear family, medical complications, caesarean delivery, bad relationship with husband, late pregnancy after marriage, multiparity and bad health of baby with NICU admission were few factors considered to be more effective for PP. In a previous study, poverty was found to be an effective factor for PP. ${ }^{26}$ In this study we didn't find poverty to be an effective factor for post-partum, as the woman visited tertiary care centre were from middle class and lower middle-class background. Similar results were published in other studies. ${ }^{28}$ Some studies showed that working woman was under more risk of PP. ${ }^{29}$ In the present study we also found similar results. Association of PP and working status of women was not signed earlier, but in our study, we found in to be a significant factor. Hegde $S$ et al and Milgrom $\mathbf{J}$ et al, reported association of PP with the planning of pregnancy, type, and mode of delivery. ${ }^{16,34}$ In this study, we found the woman undergone caesarean, with medical complications such as diabetes, eclampsia, pre-eclampsia, anaemia, hypertension, PCOD and unplanned pregnancy to be more under risk of severe PP. Similar results were published earlier in India. ${ }^{15,16}$ Indian society is a male dominating society and therefore male childbirth is entrenched, and female childbirth is considered as a stress factor in families. In few studies published earlier from Karnataka, Tamil Nadu, and Goa the same results are verified. ${ }^{25}$ In this study authors also find the birth of a female girl to a stress generating factor, but comparatively less. If the women already have a female child then the prevalence of PP is found but it was not significant, as reported earlier. Authors didn't find family history of stress to be an important factor for PP in our study. Authors also found woman has a baby in the first year of their married life to be less significant for PP, whereas a woman with delayed pregnancy was an effecting factor of PP. In such cases, several medical illnesses related to infertility also played a major role. In rural India, postnatal care plays a major role in PP, because it is rendered by the midwives (ANM and ASHA) for near about every 5000 of the rural population. ${ }^{34}$ But in this study, the study background was urban and postnatal care was not provided by ANM. In this study the woman with their child admitted in NICU was found under severe PP. ${ }^{35,36}$

Limitations of this study were the woman with abortions and stillbirth were not available for follow-ups during the study tenure, therefore no data of PP was available in such woman. In this study, we also avoided the woman with domestic violence, gender preference. The study was conducted on the woman appearing in the tertiary care center. The woman not attending the tertiary care center are not mentioned and not studied.

\section{CONCLUSION}

Postpartum is a disorder appearing in a women's life with a prevalence of 20-21\%. Medical illness during pregnancy, NICU admission of the new-born, delayed childbirth after marriage, caesarean, nuclear family, multiparity, bad relations with husband and in-laws played a significant role in the appearance of PP, whereas education status of the woman, birth of the female child, family history of depression, were also found responsible for PP but less significant. Postpartum (PP) screening plays an important role in postnatal care. Feasible trials and screening of PP at the root level are required in an Indian woman.

Funding: No funding sources

Conflict of interest: None declared

Ethical approval: The study was approved by the Institutional Ethics Committee

\section{REFERENCES}

1. World Health Organization. International Statistical Classification of Diseases and Related Health Problems $10^{\text {th }}$ Revision (ICD10). Available at: http:/ /apps.who.int /classifications/apps /icd/icd10online /Published2007. Accessed on $14^{\text {th }}$ February 2021.

2. Pearlstein T, Howard M, Salisbury A, Zlotnick C. Postpartum depression. Am J Obstet Gynecol. 2009;200:357-64.

3. Ali NS, Ali BS, Azam IS. Postpartum anxiety and depression in peri-urban communities of Karachi, Pakistan: aquasi experimental study. BMC Public Health. 2009;9:384.

4. Chaaya M, Campbell O, Kak F, Shaar D, Harb H, Kaddour A. Postpartum depression: prevalence and determinants in Lebanon. Arch Womens Ment Health. 2002;5(2):6572.

5. Rahman A, Iqbal Z, Harrington R. Life events, social support and depression in child birth: perspectives from a rural community in the developing world. Psychol Med. 2003;33:1161-7.

6. Regmi S, Sligl W, Carter D, Grut W, Seear M. A controlled study of postpartum depression among Nepalese women: validation of the Edinburgh postpartum depression scale in Kathmandu. Trop Med Int Health. 2002;7:378-82.

7. Husain N, Bevc I, Husain M, Chaudhry I, Atif N, Rahman A. Prevalence and social correlates of postnatal depression in a low income country. Arch Womens Ment Health. 2006;9:197-202.

8. Savarimuthu R, Ezhilarasu P, Charles H, Antonisamy B, Kurian S, Jacob K. Post-partum depression in the community: a qualitative study from rural South India. Int J Soc Psychiatry. 2010;56:94-102.

9. Anoop S, Saravanan B, Joseph A, Cherian A, Jacob KS. Maternal depression and low maternal intelligence as 
risk factors formal nutrition in children: a communitybased case-control study from South India. Arch Dis Child. 2004;89:325-9.

10. Patel V, Rodrigues M, DeSouza N. Gender, poverty, and postnatal depression: a study of mothers in Goa, India. Am J Psychiatry. 2002;159:43-7.

11. Chandran M, Tharyan P, Muliyil J, Abraham. Postpartum depression in a cohort of women from a rural area of Tamil Nadu, India. Incidence and risk factors. Br J Psychiatry. 2002;181:499-504.

12. Chaudron LH. Postpartum depression: what pediatrician needs to know. Pediatr Rev. 2003;24(5):154-61.

13. Posmontier B, Horowitz JA. Postpartum practices and depressive prevalences: technocentric and ethno kinship cultural perspectives. J Transcult Nurs. 2004;15:34-43.

14. Mancini F, Carlson C, Albers L. Use of the postpartum depression screening scale in a collaborative obstetric practice. J Midwifery Womens Health. 2007;52(5):42934.

15. Bennett HA, Einarson A, Taddio A, Koren G, Einarson TR. Prevalence of depression during pregnancy systematic review. Obstet Gynecol. 2004;103:698-709.

16. Hegde S, Latha KS, Bhat SM, Sharma PS, Kamath A, Shetty AK. Postpartum depression: prevalence and associated factors among women. Indian $\mathrm{J}$ Women Health Issues Care. 2012;1:13-7.

17. Chandran M, Tharyan $\mathrm{P}$, Muliyil J, Abraham. Postpartum depression in a cohort of women from a rural area of Tamil Nadu, India. Incidence and risk factors. Br J Psychiatry. 2002;181:499-50.

18. Gupta S, Kishore J, Mala YM, Ramji S, Aggarwal R. Postpartum depression in North Indian women: prevalence and risk factors. J Obst Gynaecol India. 2013;63(4):223-9.

19. Suguna A, Naveen R, Surekha A. Postnatal depression among women attending a rural maternity hospital in South India. Ntl J Community Med. 2015;6(3):297-301.

20. Trends in maternal mortality: 1990 to 2015: estimates by WHO, UNICEF, UNFPA, World Bank Group and the United Nations Population Division. Geneva: World Health Organization; 2015. Available at: http://apps.who.int/iris/bitstream/10665/194254/ 1/9789241565141_eng.pdf?ua $=1$. Accessed on $25^{\text {th }}$ August 2017.

21. Upadhyay RP, Chowdhury R, Salehi A, Sarkar K, Singh SK, Sinha B, et al. Postpartum depression in India: A systematic review and meta-analysis. Bull World Health Organ. 2017;95:706-17C.

22. Cox JL, Holden JM, Sagovsky R. Detection of postnatal depression: development of the 10-item edinburgh postnatal depression scale. $\mathrm{Br} \mathrm{J}$ Psychiatry. 1987;150:782-6.

23. Wani RT. Socioeconomic status scales-modified Kuppuswamy and Udai Pareekh's scale updated for 2019. J Family Med Prim Care. 2019;8:1846-9.

24. Sookhoo D, Race ethnicity, culture and childbirth. In: Squire editor. The Social Contex to Birth. Oxon, England: Redcliffe publishing Ltd; 2009: 85.
25. Hegde S, Latha K, Bhat S, Sharma P, Kamath A, Shetty A. Postpartum depression: prevalence and associated factors among women in India. J Women's Health, Issues Care. 2012;1(1):1-7.

26. Ghubash R, Abou-Saleh MT. Postpartum psychiatric illness in Arab culture: prevalence and psychosocial correlates. Br J Psychiatry. 1997;171:65-8.

27. Nhiwatiwa S, Patel V, Acuda W. Predicting postnatal mental disorder with a screening questionnaire: a prospective cohort study from Zimbabwe. J Epidemiol Community Health. 1998;52:262-6.

28. Tannous L, Gigante LP, Fuchs SC, Busnello ED. Postnatal depression in Southern Brazil: prevalence and its demographic and socioeconomic determinants. BMC Psychiatry. 2008;8:1

29. Cooper PJ, Tomlinson M, Swartz L, Woolgar M, Murray L, Molteno C. Post-partum depression and the mother-infant relationship in a South African peri-urban settlement. Br J Psychiatry. 1999;175:554-8.

30. Pate V, DeSouza N, Rodrigues M. Postnatal depression and infant growth and development in low income countries: a cohort study from Goa, India. Arch Dis Child. 2003;88:34-7.

31. Stewart RC, Bunn J, Vokhiwa M, Umar E, Kauye F. Common mental disorder and associated factors amongst women with young infants in rural Malawi. Soc Psychiatry Psychiatr Epidemiol. 2010;45:551-9.

32. Ghubash R, Abou-Saleh MT. Postpartum psychiatric illness in Arab culture: prevalence and psychosocial correlates. Br J Psychiatry. 1997;171:65-8.

33. Milgrom J, Gemmill AW, Bilszta JL, Hayes B, Barnett B, Brooks J, et al. Antenatal risk factors for postnatal depression: a large prospective study. J Affect Disord. 2008;108:147-57.

34. Malik G. Role of auxiliary nurse mid wives in National Rural Health Mission. Nurs J India. 2009;100:88-90.

35. Ministry of Health and Family Welfare, Government of India. National Health Mission; 2013.

36. International Institute for Population Sciences (IIPS). District level household and facility survey (DLHS-3), 2007-08: India: Key Indicators: States and Districts, Mumbai: IIPS, 2010. Available at: http://www.rchiips.org/state-fact-sheet-rch3.html. Accessed on $5^{\text {th }}$ December 2014.

Cite this article as: Rashmi AG, Shubhashri NS. Validation of Edinburgh post natal depression scale in post-natal woman from a tertiary referral center in South India. Int J Reprod Contracept Obstet Gynecol 2020;9:3439-4. 